\title{
Primed Low Frequency Transcranial Magnetic Stimulation Effects on Smoking Cue-Induced Craving
}

\author{
M. Flores-Leal, E Sacristán-Rock, L. Jiménez-Ángeles, J. Azpiroz Leehan
}

UAM-I, Centro Nacional de Investigación en Imagenología e Instrumentación Médica.

\section{ABSTRACT}

Repetitive Transcranial Magnetic Stimulation (rTMS) has shown the potential to reduce craving to smoke and the amount of cigarettes smoked. When low frequency rTMS is preceded by a priming session the cortical inhibitory effects are enhanced provoking a lasting performance. In this study we evaluate the brain regional activations and self-reported mood effect of one session of primed low frequency rTMS over the left dorsolateral prefrontal cortex (DLPFC) in response to smoking- related cues during temporary nicotine abstinence. Ten moderate nicotine dependent subjects participated in a crossover design, comparing a single session of active versus sham stimulation. After treatment, a functional Magnetic Resonance Imaging (fMRI) study was performed in all participants while completing a block-design cue reactivity paradigm. Our measures also included self-reported craving and mood score before and after every rTMS session. The number of daily smoked cigarette in a one week around period was also recorded. The results show that self-reported cravings were lower following the active stimulation; significant activation was found in areas associated with emotion control (anterior cingulate gyrus and subgenual area) and episodic memory (precuneus and posterior cingulate gyrus) as a result of the stimulation. No significant difference was found in the number of cigarettes smoked and mood scores between the sham and active condition during the one week period records. This study confirms the previous evidence that rTMS can reduce cigarette cravings and provides evidence of the neural mechanism of action that take place in order to achieve these neuromodulation effects.

Keywords: rTMS, fMRI, nicotine craving, priming.

Correspondencia:

Miguel Flores Leal

UAM-I, Centro Nacional de Investigación en Imagenología e Instrumentación Médica.

Correo electrónico: miguel.flores@mail.com
Fecha de recepción: 14 de julio de 2015

Fecha de aceptación: 30 de octubre de 2015 


\section{RESUMEN}

La Estimulación Magnética Transcranea repetitiva (EMTr) ha demostrado ser capaz de reducir el deseo por fumar y el consume de cigarrillos. Cuando una baja frecuencia de EMTr es precedida por una sesión de primado, los efectos inhibidores de la corteza cerebral aumentan y también su duración. En este estudio se evalúan las activaciones regionales del cerebro y el efecto en el estado de ánimo auto-reportado de una sesión de EMTr de baja frecuencia primada sobre la corteza dorsolateral prefrontal izquierda en respuesta a estímulos visuales relacionados con el tabaco durante una abstinencia temporal a la nicotina. Diez sujetos con dependencia moderada a la nicotina participaron en un experimento de diseño cruzado, comparando una sola sesión de estimulación activa contra una simulada. Después del tratamiento, se llevó a cabo un estudio de Imagen por Resonancia Magnética funcional (IRMf) en todos los participantes mientras llevaban a cabo un paradigma visual de bloques. Las mediciones incluyeron una puntuación auto-reportada del deseo por fumar y estado de ánimo antes y después de cada sesión de EMTr. Los resultados muestran que el deseo por fumar era menor luego de una sesión activa de estimulación; se encontraron activaciones significativas en áreas asociadas con el control emocional (giro del cíngulo anterior) y memoria episódica (precúneo y giro del cíngulo posterior) como resultado de la estimulación. No se encontró diferencia significativa en el número de cigarros fumados entre la sesión activa y simulado durante el periodo evaluado. Tampoco se registraron diferencias en las evaluaciones de estado de ánimo luego del tratamiento. Este estudio confirma la evidencia previa de que la EMTr puede reducir el deseo por fumar y proporciona evidencia del mecanismo de acción neural que se lleva a cabo para lograr estos efectos neuromoduladores.

Palabras clave: EMTr, IRMf, tabaquismo, primado.

\section{INTRODUCTION}

Transcranial magnetic stimulation (TMS) is a non-invasive method that uses a rapidly changing electromagnetic field to induce electric currents in the brain and stimulate nerve cells in a small cortical region.

TMS can produce different effects on the brain depending on the cortical region being stimulated, the frequency of stimulation, intensity and coil position. Repetitive Transcranial Magnetic Stimulation (rTMS) can produce measurable effects lasting for minutes to hours after a train of pulses [1]. In general, rTMS at frequencies greater than $1 \mathrm{~Hz}$ are excitatory, and less than $1 \mathrm{~Hz}$ inhibitory, what are some-times called virtual lesions. Recent studies suggest that when low frequency rTMS is preceded by a brief pretreatment with stimulation in the $5-6 \mathrm{~Hz}$ range, inhibition effect is greatly increased
[2]. This priming stimulation offers a new method of enhancing the depressant effect of low frequency rTMS in recent clinical applications. Thus, inhibitory effect is truly virtual and temporary, rTMS over some cortical regions can produce a transient disruption of behavior; this has shown the technique's potential as a treatment for psychiatric disorders, compulsive disorders, and addiction [3]. However, a priming pulse of $6 \mathrm{~Hz}$ can potentiate the inhibitory effect of $1 \mathrm{~Hz}$ rTMS on cortical excitability, it may not necessary inhibit brain activity when applied to other regions of the cortex.

The effect of TMS on addictions has been tested in several studies and there is evidence that it could be effective in reducing nicotine craving and consumption [4] as well as alcohol and cocaine craving [5], and it might represent a potential therapeutic tool for treating addiction. These studies 
show that high frequency rTMS over the Dorsoloteral Prefrontal Cortex (DLPFC) can reduce craving and consumption but have some limitations: besides the self-reported craving and consumption measures, no other outcome measure was assessed.

It is known that TMS does not only affect targeted region but can also impact distant brain areas that are functionally and anatomically connected with the stimulated area [6]. Available evidence seems to indicate that high frequency rTMS applied to right DLPFC has significant cross-hemispheric effects that induce an activity inhibition in left DLPFC [5]. These findings suggest that reducing craving levels could be achieved by suppressing the left DLPFC. In this line of reasoning, we hypothesize that low frequency rTMS applied to left DLPFC would reduce craving levels in response to smoking related visual stimuli.

The combination of brain stimulation and functional magnetic resonance (fMRI) allows for more direct examination of the role of circuit activity in brain behavior relationships required for a comprehensive assessment of the treatment effects [6]. New evidence suggests the DLPFC plays an important role in cigarette craving when smokers are exposed to a drug cue [7], particularly modulating their response to conditioned smoking cues depending on expectancy levels.

In this study we used a psychometric response scales and fMRI to examine the effect of priming pretreated low frequency rTMS over the left DLPFC in smokers' response when exposed to drug related cues after an abstinence period. Additionally, we assessed cigarette consumption during a week period in order to evaluate the priming potentiation effect of the inhibitory response in the long term.

\section{MATERIAL AND METHODS}

\section{Participants}

Twelve right handed smokers were recruited trough social media advertisements and individually interviewed for suitability. Two smokers were excluded from the analysis due to image artifacts caused by a malfunction in the main scanner's antenna, leaving a total of 10 smokers (see Table 1). Participants were eligible to take part if they were between the ages of 18-50 scored 5-8 in a Fagerström Test for Nicotine Dependence, had been smokers for 2 years or more, smoked at least 5 cigarettes a day and were not currently making a serious attempt to quit smoking or using a nicotine replacement therapy products. Subjects were also required to comply with all the security aspects necessary for the fMRI scanning.

The exclusion criteria also included alcohol abuse disorder, psychiatric disorder medication use, previous neurosurgery or any other chronic medical condition. Participants gave written informed consent to participate in the study and approval was obtained from the research ethics committee of the institution.

\section{Study design}

Within a randomized, single-blind, shamcontrolled, crossover design, each subject received a trial of active and a trial of sham stimulation with at least one week interval between treatments. Stimulation order followed a computer generated randomized disposition. Participants were asked to abstain smoking 6 hours prior to the stimulation sessions.

Craving to smoke as well as other negative mood states including anxiety, discomfort and sadness were measured with a $10-\mathrm{cm}-$ long visual analogue scale, applied before and immediately after the stimulation treatment. 
Table 1: Demographic and smoking characteristics of 10 participants

\begin{tabular}{lc}
\hline Variable & Value (Mean $\pm \mathrm{SD}$ ) \\
\hline General characteristics & \\
Age (range, 22-38) & $27.5 \pm 4.9$ \\
Gender (M/F) & $5 / 5$ \\
Smoking characteristics & $11.6 \pm 4.1$ \\
Cigarettes per day (range 5-22) & $5.9 \pm 0.8$ \\
FTND* score (range 5-8) & $9.9 \pm 4.2$ \\
\hline Years smoking (range 5-19) & *FTND = Fagerström Test for Nicotine Dependence \\
\hline
\end{tabular}

Participants were also required to keep a record of the number of cigarettes smoked during a week period before and after every stimulation trial.

\section{TMS treatment}

All participants underwent the rTMS treatment using a MagVenture MagPro R30 system with a figure-8 coil de-sign, the procedure was performed in a silent room located next to the MRI scanner control area. Participants were asked to sit down in a comfortable armchair and the coil was fixed in position using a metal brace. The Motor Threshold (MT) was determined using the equivalent Observation of Movement (OM) method, according to this, $\mathrm{OM}$ is a reliable method to obtain the MT were the Motor Evoked Potential (MEPs) are replaced with observed movements of the thumb or fingers [8]. Cortical stimulation was delivered using the figure-eight coil at a rate of $0.2 \mathrm{~Hz}$ to the left motor cortex to induce a visible twitch in the Abductor Pollicis Brevis (APB) muscle of the right hand on 5 of 10 pulses delivered.

The left DLPFC stimulation site was defined using the Beam F3 location system [9] that takes into account only three skull measurements to locate the F3 position given by the 10-20 system which corresponds to the left DLPFC.

Priming pretreatment stimulation was delivered before each low frequency stimulation trial. Priming dose consisted of
$6 \mathrm{~Hz}$ rTMS stimulation, (20 trains lasting 5 sec separated by $25 \mathrm{sec}$ ) for a total of 600 pulses applied to left DLPFC. TMS intensity was set at $90 \%$ of the MT of each subject following previously reported safety and timing parameters needed to enhance the depressant effect of subsequent low frequency rTMS [2].

After priming, $1 \mathrm{~Hz}$ rTMS at $115 \%$ of individual MT was delivered to the exact same cortical area for a total of 1200 pulses to induce a stable decrease in excitatory transmission.

Active trial: The coil was positioned over the left DLPFC, using previously described stimulation parameters, priming pre-treatment was applied during 10 minutes followed by 20 minutes of low frequency stimulation at $1 \mathrm{~Hz}$.

Sham trial: The sham stimulation was delivered with the exact same power parameters, timing and location as the active trial but using a 1 -wing $90^{\circ}$ coil position, this is achieved by tilting the figure-eight coil such that only one wing touches de scalp at a 90degree angulation [10]. This configuration provides comparable acoustic and sensation artifacts.

Following stimulation, a second visual analogue scale test was assessed, as it has been done before starting the trial. Then subjects were placed in the MRI scanner bed, headphones were used to minimize scanner noise and subject communication.

\section{Imaging Parameters}

Image acquisitions were carried out using a 3 Tesla Philips scanner. Blood oxygen leveldependent (BOLD) signals were acquired using a gradient-echo echo-planar imaging $(\mathrm{EPI})$ sequence $(\mathrm{TR}=3000 \mathrm{~ms} ; \mathrm{TE}=30$ $\mathrm{ms}$; flip angle $=90^{\circ} \mathrm{FOV}=230 \mathrm{~mm} \mathrm{x}$ $108 \mathrm{~mm}$, matrix $=96 \times 96$ ). A standard eight channel head coils was used to acquire 338 continuous images, each image consisted of 27 contiguous slices ( $4 \mathrm{~mm}$ thick) parallel to the anterior commissure posterior commissures. 
Following the fMRI runs, a T1-weighted structural imaging was acquired using a fast spin-echo sequence (Voxel size $=1.1 \times 1.1 \mathrm{x}$ $0.6 \mathrm{~mm})$.

\section{Stimulus presentation}

A smoking-cue paradigm was used to induce cigarette craving following previously established methods [7]. We used Eprime software enhanced graphical interface for stimulus presentation in coordination with a two button response box interface (Current Designs) for data collection. Visual stimulus were presented onto an fMRI safe display located behind the scanner, and were viewable by means of a mirror mounted on the MRI head coil.

Participants were positioned in the MRI bed and after displaying instructions the acquisition sequence started. Visual paradigm consisted of six video blocks alternated with target and attention screens. Each video lasted 2 minutes and contained ten different scenes (12 seconds each).

Smoking related video.- Scenes were similar in framing and portrayed individuals, differing in age and gender, engaging in smoking related activities such as opening a cigarette pack, lighting up a cigarette, blowing smoke or talking while smoking.

Neutral video.- The clips were similar to that of smoking related video, however, they portrayed individuals in non-smoking activities like working, having a conversation or resting.

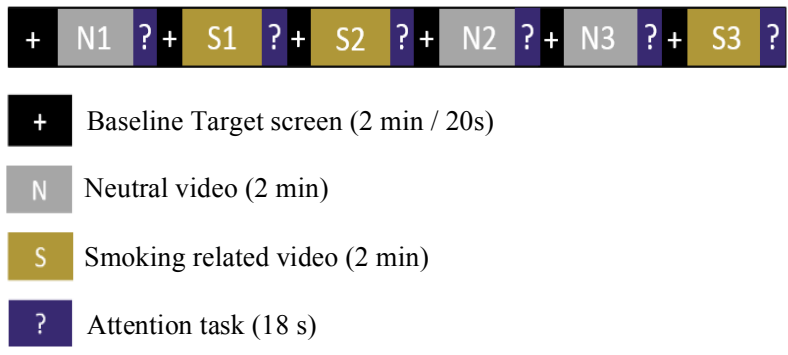

Figure 1: Block stimulus schematic. Neutral and Smoking videos alternates with baseline target and attention feedback screen.
Stimulus sequence and duration are detailed on Figure 1.

\section{fMRI Data Analysis}

Acquisitions were analyzed using SPM 8 Software (www.fil.ion.ucl.ac.uk/spm) Images were slice-timed, reoriented and realigned to the first volume. Next, volumes were normalized to an SPM EPI- template and spatial smoothing was performed using a 6 mm FWHM Gaussian kernel.

Each participant's data were analyzed using a general linear model with a synthetic hemodynamic response function to model responses to each stimulus type (smoking, neutral and attention task). Having created smoking $>$ neutral cue t-contrast images for each subject, a second level random analyses was performed on each comparison of interest. An uncorrected statistical threshold $(\mathrm{p}<0.001)$ and a voxel cluster threshold of 25 were used in order to determine the main activation peaks on MNI coordinates that were later associated with an anatomical structure and functional region using Xjview (http://www.alivelearn.net/xjview8) anatomical database. Results are listed in Table 2 and illustrated in Figure 2.

Table 2. Peak activation coordinates for active and sham stimulation $(n=10)$.

\begin{tabular}{|c|c|c|c|c|c|c|}
\hline \multirow[t]{2}{*}{ Side } & \multirow[t]{2}{*}{ Brain area } & \multirow[t]{2}{*}{$\mathrm{BA}$} & \multicolumn{3}{|c|}{ Coordinates } & \multirow[t]{2}{*}{$\mathrm{T}$} \\
\hline & & & $\mathrm{x}$ & $\mathrm{y}$ & $\mathrm{z}$ & \\
\hline \multicolumn{7}{|c|}{ Active Trial } \\
\hline $\mathrm{R}$ & Sub-gyral & & 20 & -6 & 56 & 6.68 \\
\hline $\mathrm{L}$ & Sub-gyral & & -26 & 16 & 26 & 6.53 \\
\hline $\mathrm{L}$ & Inferior Parietal lobe & 39 & -52 & -66 & 40 & 5.83 \\
\hline $\mathrm{L}$ & Inferior Parietal lobe & & -44 & -26 & 28 & 5.59 \\
\hline $\mathrm{L}$ & Cingulate Gyrus & 31 & -8 & -40 & 40 & 5.41 \\
\hline $\mathrm{L}$ & Precuneus & & -16 & -54 & 36 & 5.33 \\
\hline $\mathrm{L}$ & Anterior Cingulate & 25 & -4 & 18 & -2 & 5.31 \\
\hline $\mathrm{L}$ & Insula & & -40 & 6 & 16 & 5.19 \\
\hline $\mathrm{L}$ & Anterior Cingulate & 32 & -12 & 40 & 12 & 4.57 \\
\hline \multicolumn{7}{|c|}{ Sham Trial } \\
\hline $\mathrm{L}$ & Lentiform nucleus & & -24 & 2 & -6 & -5.96 \\
\hline $\mathrm{L}$ & Putamen & & -16 & 6 & 10 & -5.37 \\
\hline $\mathrm{R}$ & Middle Temporal gyrus & & -56 & -64 & 10 & -4.45 \\
\hline
\end{tabular}




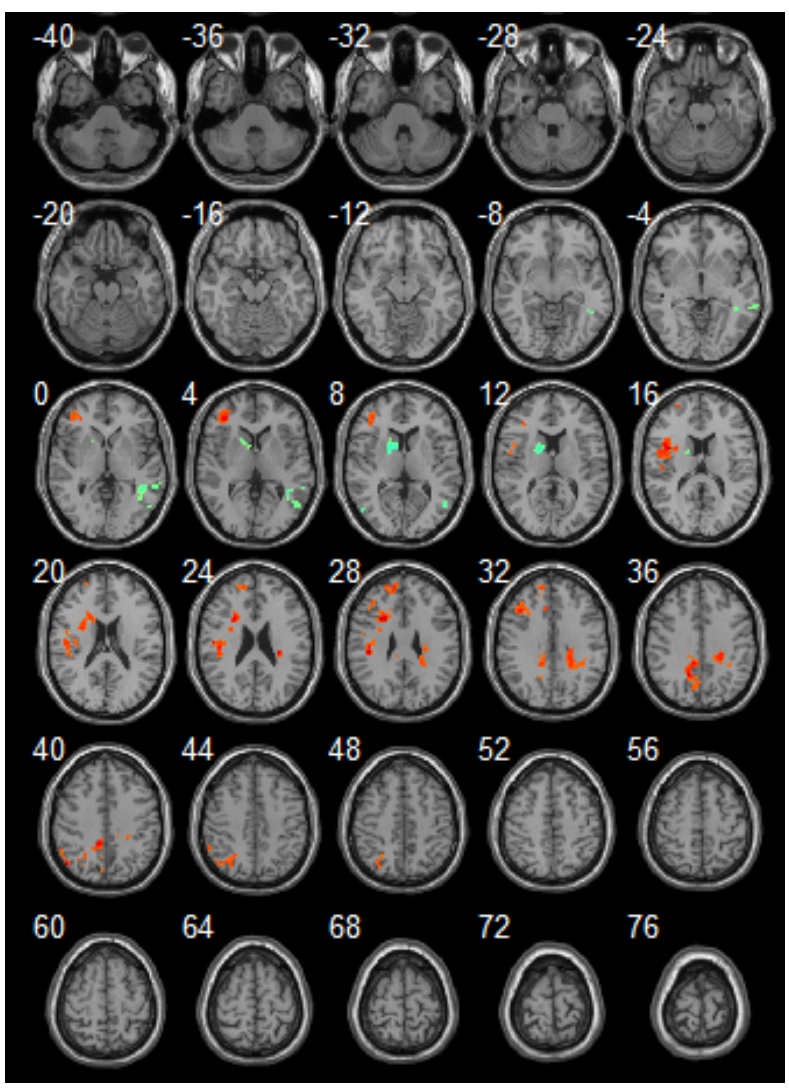

Figure 2: Sectional view of increased activity areas using an Active treatment (red) $>$ Sham treatment (blue) contrast (unc. $\rho=0.001$, voxel threshold $\geq 25$, $\mathrm{n}=10)$. Regardless positive or negative connotation, both activations provide complementary information about each treatment condition.

\section{RESULTS}

The scores obtained from the self-reported craving analogue test were compared within and across treatment type (active or sham) using repeated measures analysis of variance ANOVA followed by a post-hoc Tukey test. Significant difference $(\rho=0.047)$ was found between post-sham and postactive groups (see Figure 3a). Following the same procedure, the mood scores were also analyzed but no significant difference was found between groups. Each participant smoked an average of 9.98 cigarettes per day. The daily smoked records were analyzed using a repetitive measures ANOVA but no significant change was observed in the
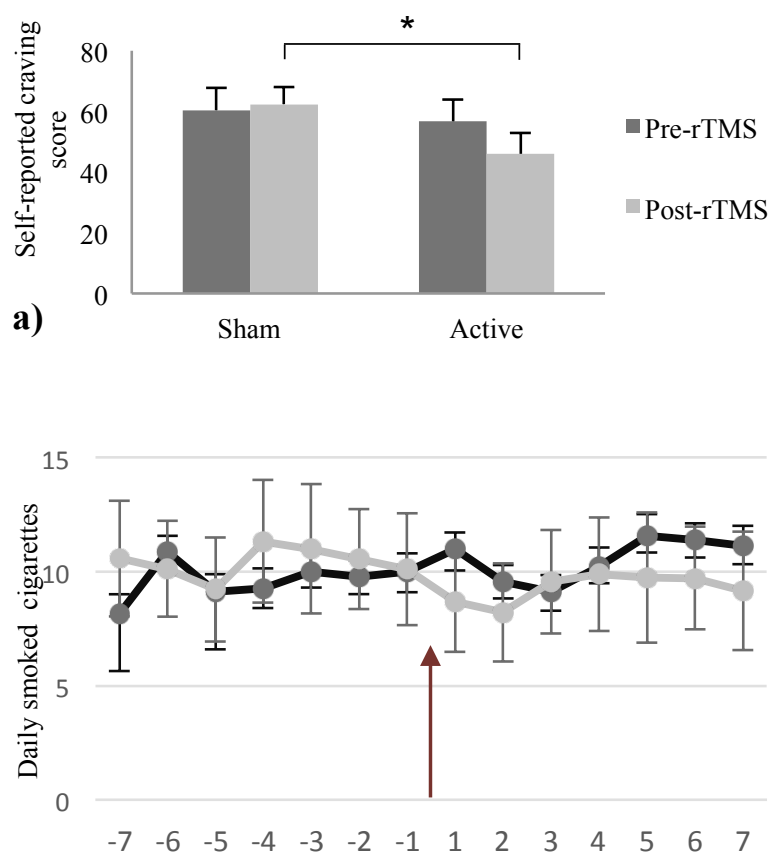

b)

Figure 3. Craving and smoking habits during the experiment a) Effect of priming pretreated low frequency rTMS on the self-reported craving score through all trials. Mean \pm SEM; $\mathrm{n}=10, \mathrm{Y}$ axis $=100$. *denotes significant difference $(\rho<0.5)$. b) Daily smoked cigarettes during the 7 day period before and after each rTMS session. The arrow indicates when the stimulation is applied. Mean \pm SEM; $n=10$.

cigarette consumption during the week period after active and sham rTMS treatment (see figure $3 \mathrm{~b}$ ).

Comparison between stimulation and control conditions from the paired T-test whole brain analysis were obtained using an active-treatment $>$ sham-treatment contrast, significant activation clusters (unc. $p<0.001$, cluster size $\geq 25$ ) were found in several brain regions, mostly on the left hemisphere limbic system structures, commonly related to rational cognitive functions (Anterior Cingulate Cortex), episodic memory and awareness (Posterior Cingulate Cortex, Precuneus. Brain activity was also found in a functional region (Brodmann area 25) that keeps an intrinsic functional connectivity with the DLPFC, recently discovered through TMS depression treatments [11]. 
Negative activations obtained from the complementary paired T-test whole brain analysis using a sham-treatment>activetreatment contrast revealed activity in dopamine regulation structures (Putamen) and visual recognition (Middle temporal gyrus). Positive and negative activation are displayed in a whole brain 3D model to facilitate region identification (see fig. 4).

\section{DISCUSSION}

The present study supports evidence that low frequency rTMS delivered to the left DLPFC can reduce the subjective craving rates of nicotine dependent subjects when exposed to drug related cues. Furthermore, we suggest the possible neural mechanism behind this response shift measured after the stimulation treatment involving a transient disruption of the corticolimbic brain regions implicated in the process of drug addiction and particularly craving [12].

To our surprise, most of the activation areas associated with the stimulation effect were registered in deeper brain structures, which are anatomical and functionally connected with the DLPFC but out of reach of the transient magnetic field effect. This suggests that the neuromodulator effect could be caused not only by the temporal inhibition of the neural mechanism that characterized the DLPFC but mainly due to a linked emotion and neurotransmitter regulation effect of deeper brain areas projections in the processing and executive task of the prefrontal cortex [13].

Negative activation turned to be as interesting as the positive ones, even though its connotation, they cannot be considered as hippoactivations rather as control treatment related activations and they can be interpreted as the regular response to smoking-related visual stimuli. Main negative activations located at the Putamen confirm the role of this area in neurotransmitters regulation when addicts are exposed to drug related cues [14].

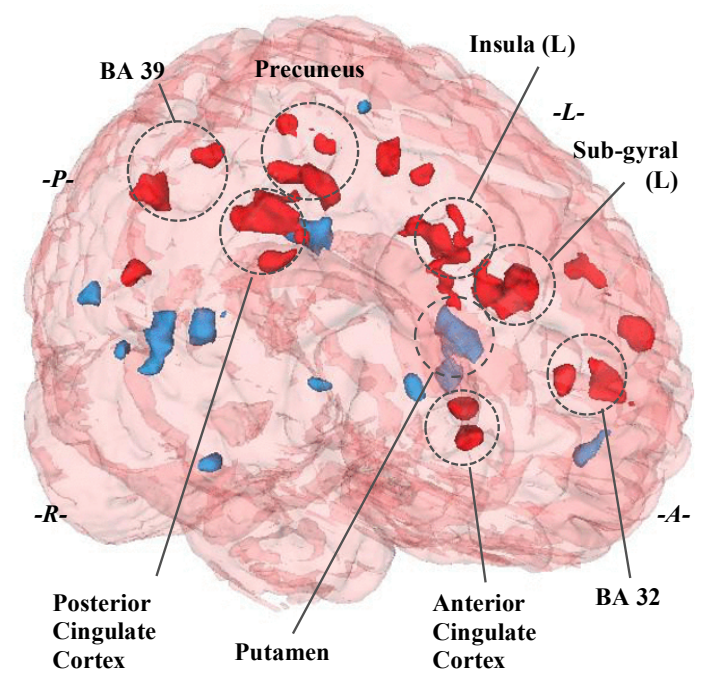

Figure 4. Whole brain 3D render showing main activation volumes in Active treatment related areas (Red) and Sham related areas (blue). $(p<0.01)$ unc. Minimum cluster size $=25$. Abbreviation: $\mathrm{BA}=$ Brodmann Area.

The analysis also found white matter activations, located between the stimulated area and the deep functional structures that revealed activity. Although the study of white matter activations in fMRI remains controversial [15], these findings may suggest the presence of an underlying neural pathway connecting both brain areas.

It is worth mentioning that mood changes were noticed, particularly sadness, caused by the stimulation treatment, even though it was not significant, it showed an interesting trend to increase after active stimulation. This confirms the distant effect of rTMS in the corticolimbic regions, mainly in the subgenual cingulate, implicated in mood regulation [16]. Our findings support the idea that is possible to achieve craving response regulation using a combination of high and low frequency rTMS applied to the left DLPFC.

There are some potential limitations in this study. First, we did not perform craving measures in the following hours after the stimulation which would be necessary to evaluate the lasting effect of priming; instead we focused in creating a stronger craving sensation using an immediate expectancy 
to smoke where the role of DLPFC is highly increased [7]. In addition, cigarette consumption during the experiment day was not registered by the participants.

Although we observed consistent activations in the image analysis, which can be related with the stimulation effect, most of them were not capable of surviving a Family Wise Error (FWE) correction. This could be caused by several methodical limitations along with the small group of subjects included in the analysis. To begin with, craving to smoke evoked by the visual stimuli may not be strong enough to cause significant activation in moderate smokers. In this regard, evidence suggest that the use of additional stimulus like tactile or even cigarette smoke odor could help increasing the craving response [17].

It is important to mention that this group of nicotine dependence was selected in order to achieve tolerable levels of craving and anxiety during the abstinence period, which we considered necessary to go through the whole treatment without causing excessive distress, diminishing attention and performance during the visual paradigm.

Furthermore, we build our fMRI image statistical analysis based on the idea that a contrast between treatment groups would highlight the true effect of stimulation. Although these results have provided a considerable validation of primed low frequency rTMS as an approach to regulate craving response on a general basis, further work should include a complementary analysis of interaction between intra-subject factors such as video type and treatment as well as individual analysis that could provide sex or age differences in pursuance of valuable information that enhance our initial results.

Finally, even temporary lower craving urges may be helpful for controlling an addiction; we think that more than one stimulation session is needed to affect consumption rate [18].

\section{CONCLUSION}

The result of the study opens a window into the mechanism of primed rTMS effects on the cue-craving control neural circuit, providing an insight into the link existing between the DLPFC stimulation and distant brain activity areas. The findings suggest that the decrease in the desire to smoke could not only be caused by a temporal disruption of a cognitive process integration area involved in craving but could also be mediated by a considerable activation of remote neural mechanism in charge of emotion regulation, modifying the typical response to smokingrelated stimuli.

Although this study demonstrated that priming pre-treatment low frequency rTMS can reduce cue-craving to smoke and possibly further investigation on priming pretreated rTMS is needed to develop an effective smoke cessation treatment.

\section{ACKNOWLEDGEMENTS}

We thank the team of professionals at Ci3m (Centro Nacional de Investigación en Imagenología e Instrumentación Médica) for the image acquisition and technical support along the experiment. We also thank Jorge Armony, $\mathrm{PhD}$, for his valuable advice on fMRI processing. The first author thanks CONACYT for the scholarship (335698) granted during his master studies.

\section{REFERENCES}

1. A. Pascual-Leone a,b, J.M. TormosMuñoz a,b. "Estimulación magnética transcraneal: fundamentos y potencial de la modulación de redes neurales específicas." Rev Neurol, vol. 46, pp. 3-10, 2008. 
2. Iyer, M. B., Schleper, N. Wassermann, E. M. "Priming stimulation enhances the depressant effect of low-frequency repetitive transcranial magnetic stimulation." J. Neurosci., vol. 23, pp. 10867-72, 2003.

3. William Beam, B.S Jeffrey J. Borckardt, Ph.D. Scott T. Reeves, M.D., and Mark S. George, M.D. "An efficient and accurate new method for locating the F3 position for prefronal TMS applications." Brain Stimul., vol. 1, pp. 50-54, 2009.

4. Eichhammer, P. et al. "Highfrequency repetitive transcranial magnetic stimulation decreases cigarette smoking." J. Clin. Psychiatry, vol. 64, pp. 951-3. 2003.

5. Camprodon, J. A., Martínez-Raga, J., Alonso-Alonso, M., Shih, M.-C. Pascual-Leone. "A. One session of high frequency repetitive transcranial magnetic stimulation (rTMS) to the right prefrontal cortex transiently reduces cocaine craving." Drug Alcohol Depend., vol. 86, pp. 91-4, 2007.

6. Christian C. Ruff, Jon Driver, and Sven Bestmann "Combining TMS and fMRI." Cortex, vol. 45, pp. 1043-1049, 2009.

7. McBride, D., Barrett, S. P., Kelly, J. T., Aw, A. Dagher, A. "Effects of expectancy and abstinence on the neural response to smoking cues in cigarette smokers: an fMRI study." Neuropsychopharmacology, vol. 31, pp. 2728-38, 2006.

8. Varnava, A., Stokes, M. G., Chambers, C. D. "Reliability of the "observation of movement" method for determining motor threshold using transcranial magnetic stimulation." J. Neurosci. Methods, vol. 201, pp. 327-32, 2011.

9. William Beam, B.S Jeffrey J. Borckardt, Ph.D. Scott T. Reeves, M.D., and
Mark S. George, M.D. "An efficient and accurate new method for locating the F3 position for prefronal TMS applications." Brain Stimul, vol. 1, pp. 50-54, 2009.

10. Lisanby, S. H., Gutman, D., Luber, B., Schroeder, C. Sackeim, H. a. Sham "TMS: intracerebral measurement of the induced electrical field and the induction of motor-evoked potentials." Biol. Psychiatry, vol. 49, pp. 460-3, 2001.

11. Fox, M. D., Buckner, R. L., White, M. P., Greicius, M. D., PascualLeone, A. "Efficacy of transcranial magnetic stimulation targets for depression is related to intrin-sic functional connectivity with the subgenual cingulate." Biol. Psychiatry, vol. 72, pp. 595-603, 2012.

12. Goldstein, R, Volkow, N. "Drug Addiction and Its Underlying Neurobiological Basis: Neuroimaging Evidence for the Involvement of the Frontal Cortex." Am J Psychiatry, vol. 159, pp. 1642-5, 2002.

13. Maddock, Richard J.; Garrett, Amy S.; Buonocore, Michael H. "Posterior cingulate cortex activation by emotional words: fMRI evidence from a valence decision task." Human Brain Mapping, vol. 18, pp. 30-41, 2003.

14. N. D. Volkow, G.-J. Wang, F. Telang, J. S. Fowler, J. Logan, A.-R. Childress, M. Jayne, Y. Ma, and C. Wong, "Cocaine cues and dopamine in dorsal striatum: mechanism of craving in cocaine addiction." J. Neurosci., vol. 26, no. 24, pp. 6583-8, 2006.

15. J. R. Gawryluk, E. L. Mazerolle, and R. C. N. D'Arcy, "Does functional MRI detect activation in white matter? A review of emerging evidence, issues, and 
future directions," Front. Neurosci., vol. 8, no. 8, pp. 1-12, 2014.

16. Drevets, Wayne C., Jonathan Savitz, and Michael Trimble. "The Subgenual Anterior Cingulate Cortex in Mood Disorders." CNS spectrums, vol. 13, no. 8, pp. 663-681, 2008.

17. T. R. Franklin, Z. Wang, J. Wang, N. Sciortino, D. Harper, Y. Li, R. Ehrman, K. Kampman, C. P. O'Brien, J. a Detre, and A. R.
Childress, "Limbic activation to cigarette smoking cues independent of nicotine withdrawal: a perfusion fMRI study." Neuropsychopharmacology, vol. 32, no. 11, pp. 2301-9, 2007.

18. Amiaz, R., Levy, D., Vainiger, D., Grunhaus, L., Zangen, A. "Repeated high-frequency transcranial magnetic stimulation over the dorsolateral prefrontal cortex reduces cigarette craving and consumption." Addiction, vol. 104, pp. 653-60, 2006. 